\title{
The significance of the personal within disability geography Nancy Worth
}

\author{
School of Geography, University of Leeds, Leeds LS2 9JT
}

Drawing on in-depth qualitative data, this article critically examines disability geography as a subfield where the personal is highly valued. The value and the risks inherent in this personal approach will be evaluated, including the usefulness of being an 'insider' and the difficulties of being reflexive and critically making use of one's positionality. The article concludes with reflections regarding how disability geography can confront its marginal status, appealing to researchers who claim no experience of disability while also supporting and encouraging those with personal experiences of disability to participate in the field.

Key words: Canada/UK/Australia, disability geography, email interviews, insider research, positionality, ableism

\section{Introduction}

In general, people - in the sense of acknowledged, autonomous, sentient beings - remain generally absent from the narratives of health geography (but rather more present in the often reluctantly related field of disability geography). (Kearns and Moon 2002, 613)

Presenting at the recent conference of Emerging New Research in Geographies of Health and Impairment (ENRGHI) was an interesting experience for someone who works within the subfield of disability geography. I was struck by the personal statements that either prefaced or were embedded within several conference presentations on disability, were almost completely absent from work in geographies of health and impairment. When presenting my work in the past, I would often begin with what brought me to the subfield of disability geography, relating the story by rote, without critically questioning why I thought it important to do so. As the conference progressed, I became interested in why work on disability in geography often evokes a declaration by the researcher of their motivations. When considering why research in disability geography didn't seem to quite fit within the conference, it became clear that not only were research outputs quite different between health and disability geography, the latter often involves an engagement at the scale of the personal.

This paper takes a look at one aspect of a larger project that examined the value of a geographical perspective in disability research by tracing the development of disability geography as a subfield, its current interests and its future possibilities. Using email interviews, the research asked the practitioners in the subfield to critically evaluate what a geographical perspective had to offer disability research, including research motivations, theoretical constructs around difference, ableism and enabling methodologies (Worth 2005). The multiple disclosures of a personal connection to disability, and the ways in which these connections are enmeshed with research in the subfield, were research findings that I was interested in exploring further.

This paper argues that disability geography can be characterised by its interest in the personal. The aim of the paper is to draw out researchers' connections to the field, discussing both the value and pitfalls of insider knowledge and reflexive writing. The positive

[page 307]

aspects of personal connections to the field include the ability to bring attention to absent voices, bringing new areas of research to the field. Moreover, the presence of geographers with personal experiences of disability offers the subfield both a way of confronting ableism in the discipline, and presents access to their unique knowledge. The most important aspect of a close relationship with disability is the advantage of making the personal political, using the emotions and experience of disability to create critical research. Instead of trying to find inherent negatives of personal engagement within disability geography, it is more appropriate to think more subtly about the risks or assumptions of what a personal connection to the field may offer. Specifically, the strong work done by many researchers in the subfield challenges the wider belief that the personal is a prerequisite, or that the field has no strong points other than the passion of its researchers. In the conclusion, I discuss what the personal nature of the subfield means for the future of disability geography, offering suggestions about possible new directions and its relationship with the rest of the discipline.

The subfield of disability geography

Disability geography has existed as a distinct subfield of geography since the early nineties, engaging with a variety of subject areas and theoretical approaches (for reviews see Imrie and Edwards 2007; Park et al. 1998). Early research in disability geography was often based on a medical model that focused on diagnosis and the impaired body. The medical model sees impairments 'as "individual medical tragedies" in which the body is conceptualised as simply failing to meet normal standards of form, ability and mobility' (Butler and Parr 1999, 3). The use of the medical model of disability was debated in a series of papers in Transactions between Golledge (1993 1996), who highlighted the practical value of research based on a medical model, and others who stressed the importance of a social model of disability that sees disabled people as oppressed by an ableist society rather than their impairments (Butler 1994; Gleeson 1996; Imrie 1996). Much work in disability geography has since been shaped by the social model, which sees modern capitalist societies as disabling. What has been unique about disability geography is its inclusion of bodily differences, valuing the individual experiences of impairment and disability in the context of an ableist society. Hansen and Philo's paper on the body and disability geography rightly labels this a 'somewhat heretical stance with respect to a "pure" social model, always being prepared to keep bodily differences securely in the picture' $(2007,495)$. Blending the inclusion of bodily difference into a social model of disability makes definitions of impairment and disability tricky for geographers. Rather than wade into the discussion of what disadvantages are caused by 'impairment effects', and which are a result of societal oppression, Shakespeare's (2006) interactional approach is helpful. He argues that 'people are disabled by society, and by their bodies', and that it is perhaps more useful to position disability and impairment on an interrelated continuum (2006, 56). Moreover, 'disabled' and 'able-bodied' are also analytically more useful as a continuum of experiences, rather than polar opposites. Disability can be experienced relatively, in particular time-spaces, depending both on environment and society. This paper attempts to think through the significance of the personal in disability geography, by using interviews with researchers in the field. 


\section{Method}

Email was used to gather the thoughts and reflections of 16 geographers citing an interest in disability geography in North America, the UK and Australia over a period of several months. Electronic communication via email proved to be an effective method of collecting data from a small network of geographically dispersed researchers, providing an efficient and cost-effective method of including a variety of voices. Moreover, according to McCoyd and Schwaber Kerson (2006, 390), when compared to telephone interviews and face-to-face interviews, 'email interviews tend to be more complete, to include more self-reflection by respondents, and to be seemingly more candid'. Other benefits of email interviews include their convenience; respondents could answer all of the questions at once or in parts, whenever they had the time. While the use of email instead of face-to-face interviews may appear unusual when the goal is to gather individual reflections, the method has been successfully used by Mahtani (2004) in her discussions about race and gender with women of colour geographers, and by Browne (2005) in her work on feminist geography pedagogy.

The process of gaining informed consent was an important step in the research design. An introductory

email explained the research and its goals, as well as details about the project's ethical review.1 A promise of anonymity could not be reasonably given, as the subfield is small and relatively close knit. Moreover, the intent to publish direct quotations from the email interview text was also made explicit. Although anonymity was expressly not given, the names have been removed from the quotations included below to prevent the identity of participants from becoming a distraction. Sixteen academics were originally contacted to participate, selected to achieve a varied Anglophone group, representing a variety of theoretical approaches. Nine complete responses were received, three emails went unanswered, and there were four regrets. This paper is based on the first section of the email interview, which relates to participants' interest in the subfield of disability geography, and how they would characterise their conceptual framework:

- How did you become interested in studying disability from a geographic perspective?

- Who or what sparked your interest in geography and disability?

- What model of disability (if any) do you use in your work? Why?

Taking a personal interest in disability geography

One might question this paper's sustained interest in who does research, rather than the research itself, but it is obvious that research does not occur in a vacuum. Instead, choices about what to research, and how, are often intensely personal decisions. Therefore, the responses included below can be seen as the starting point to explore the personal within disability geography. Answering the question, 'How did you become interested in studying disability from a geographic perspective?', eight of nine participants offered various personal ways of becoming interested in disability geography, ranging from narratives of bodily impairment and disablement, to work and familial experiences of disability as a carer/ally. My definition of a personal relationship with disability includes one's own experience, as well as experiencing disability within the family and in civil society, as all three involve a private reckoning of disability and ableism, while also providing a motivation to research these issues. In some senses this can be understood as a partial understanding of disability experience, as I realise that embodied understandings of impairment may vary significantly in these three realms.

Beginning with those who experienced disability from within their own bodies, one participant offered her personal experience of chronic illness as the starting point for thinking about disability more generally:

Becoming ill ... and experiencing first hand issues of physical and social marginalization as a disabled woman, and particularly in academic places of work, was the impetus for my becoming involved in geographic research on disability. As debilitating as my illness was ... I began to learn that it was discriminatory social attitudes and practices in places such as academia that were the most disabling of all. My 13 year long struggle for reasonable accommodation at my University, which included legal action against the University, really made the oppressiveness of our societies toward persons with impairments and illnesses hit home in a very direct way. As I began to realize how marginalizing and unfair our societies and spaces of life were to persons with impairments and illnesses it seemed to me important to put my academic skills (e.g. training as a political economic and feminist geographer) to use in advancing our understanding of disability issues.

Others became interested in the subfield after they were confronted with issues of disablement, ableism and exclusion, through job placements working with people with mental health problems or other disabilities. Again, initial personal experiences were expanded into thinking about larger processes through additional academic work:

I was drawn into the field of enquiry via the field of practice. I worked with disabled people during my undergraduate years in a respite care home for children. This neighbourhood home made me think about the issues of social acceptance and integration and the role of urban policy - this became the topic of my honours thesis. I worked for many subsequent years in care homes and as a teaching assistant in a school for disabled children. In my year off before going to University . . I I worked as a Community Service Volunteer in London, and several jobs that I undertook included assisting at day centres for people with mental health problems. I was fascinated by these centres, where they were located, and how they might help their 'clients' in building up 'normal' everyday community relations. When at university and looking around for a dissertation project, I wondered if any geographers had ever conducted work on mental health problems. To my

[309]

surprise, I found that there was a small body of work, notably a paper by Michael Dear and co-workers in the 'Annals of the Association of American Geographers'.

Several respondents mentioned personal motivations from family as inspiration to work in a new field of geography.

Two influences. First I had previously worked on geography and stigma, with special reference to 'race'. . . I felt that there were some similarities, although also differences, in the geographies of disability. The second is personal . . a daughter born in 1977 has Down Syndrome, and this brought me into a previously unknown world of intellectual disability. I got caught up in policy while acting as an advocate, but my professional interests remained historical.

Before a discussion of the personal motivations present within the subfield, it is important to recognise the influence of feminist geography on the following critique, where concepts of autobiography and 'insider status' are well explored (England 1994; Moss 1999 2001; Rose 1993 1997; 
Valentine 2002). Moreover, in other critical geographies of difference, including 'race' and sexuality, the situation of knowledge, including the value of personal motivations for research, has been important. Rose $(1997,313)$ offers a useful concept of how researchers can get at the power relations inherent in knowledge production, suggesting positionality that favours 'betweenness', where researchers claim neither a distanced objectivity nor sameness, instead attempting to locate analysis 'between researcher and researched'. Working at situatedness in this way, especially in disability geography, encourages both researchers with a personal connection to the field and those without one to share middle analytical ground. Adopting a position of betweenness may seem naive, as the research tries to employ neither a distanced objectivity nor an intimate sameness. This position of betweenness is most successful when researchers realise that the process of situating knowledge is at best partial and uncertain, as we can never completely know how power is implicated in research, nor how the research relationship is actually experienced by research participants. Nevertheless, despite its difficulties, engaging with situated knowledge works toward building research that is 'at once of substantive and theoretical interest as well as of practical significance to those with whom we work' (Katz 1994, 72).

Although there is much to be learned from feminist geography, it will be difficult for disability to become as central to the discipline as feminism has. The key difference involves distinctions between sex/gender and impairment/disability, where the first term in the binary is uncritically seen as biological, and the latter social. Feminism has progressed into the mainstream in geography by asserting that sex is also already a social construct (see Butler 1990). This becomes problematic to transfer to disability geography, as impairments are not social to the same extent - instead impairment can put a person at a bodily/biological disadvantage in a way that being a women does not (Shakespeare 2006). The added complexity of biology seems to encourage an engagement with the personal within disability geography, which has both benefits and risks to the subfield.

\section{The value of personal interest}

Personal motivations to study disability in geography can lead to the identification of missing areas in the field. In Chouinard's 1995 paper with Ali Grant, she uses her personal experience of disability to illustrate what's missing from 'the Project' in geography, where certain kinds of difference are overlooked. Chouinard uses

personal experiences to help the reader 'see' society and our discipline through others' eyes. The intention in not to evoke sympathy or pity but to encourage the reader to understand more fully the environments [she] negotiates daily. (Chouinard and Grant 1995, 139)

This is an effective way of calling attention to the ableism inherent in Western society as Chouinard's personal reflections connect with a reader's emotions and sense of empathy, while also encouraging a greater perception of what ableism means. For some disabled people, the converse situation of accounts of ableism by a person who considers themselves non-disabled 'potentially undermines the impact or significance of the research of point being made' (Kitchin 2000,34). Work by disabled geographers that expands out from personal reflections to address new areas of geographic inquiry is highly valued in the subfield. Several practitioners, particularly those who situate themselves as non-disabled, privilege work by their disabled colleagues for its insider status - both for its apparent embodied understanding of disability and impairment, as well as the political

[310]

ideal that insider research is inherently more likely to be emancipatory. One respondent commented,

The best scholarship in this area often, though not inevitably, arises from personal experience and I always prioritise in my reading and my engagement the work of disabled scholars.

Another respondent commented,

Ideally, projects would be not just 'on' such subjects, but conducted 'with' and 'for' them - and, perhaps more importantly still, there should be times when the researcher him or herself has a disability of one kind of another.

Although there is hesitancy and qualifications in both quotations, both consider disabled researchers to have access to knowledge or understanding that they do not. This access may be in part attributable to how research participants relate to non-disabled researchers. Kitchin's work suggests that in some instances

disabled people will only tell partial stories to a nondisabled researcher for fear of embarrassment or lack of empathy ... Moreover, they will, in the main make situations seem better than they really are. $(2000,34)$

The presence of researchers with personal experience of disability works at dismantling ableism within geography, by recognising the unique knowledge these researchers possess, and that it is unethical to work in the field without trying to make space for the absent voices of disabled people. Working within disability studies, the work of Beazley et al. (1997) echoes the commitment to emancipatory research practices prioritised by researchers in disability geography. They preface their work by stating:

The strong accountability we felt to disabled people may seem rather self-important and pretentious, but personal commitments to disabled family members and colleagues made it impossible to draw back from securing the adequate and primary inclusion of disabled people's own voices. (1997, 148)

While self-effacing, this comment connects personal links to disability to a strong commitment to confront ableism. This sense of obligation is echoed by one of my respondents, who comments,

l've always been interested in issues of social justice and civil rights and with righting the wrongs of society. The lives of many disabled people are unjust and so it seemed that this was a natural area of concern and study for me.

Besides the passionate dedication to the emancipatory aspect of the subfield, researchers with a personal connection to the field often have unique knowledge that can be helpful to pick apart complex experiences of disability. In Moss' work on chronic illness, she was able to sort through aspects of her embeddedness having to do with illness and link some of her own positionings with women in the study. (Moss and Matwychuk 2000, 90; also see Shah 2006)

Evident from the interview excerpts above, researchers use personal motivations to focus on wider issues of social justice, what Moss and Matwychuk call 'moving beyond speaking as an "as a" and stating "etc." toward implementing insights about difference into political actions' (2000, 84). They describe a process of critical reflexivity, where researchers with personal claims to disability can connect with similar experiences related by participants, helping to sort out the multiple, complicated nature of individual experience. Moss relates,

The intensity of this experience of being ill led me to undertake research with women with chronic illness. My combination of positionings sets the context for my present struggle over what illness and disability are and who gets to define them. ... (Moss and Matwychuk 2000, 89) 
This concept of making the personal political is a central principle of feminism, but it has often left disability outside of feminist research, which has been more focused on including difference based on 'race', class and sexuality (see Morris 1992). The process of using personal experiences to relate to research participants is most successful when the multiple subjectivities of both the researcher and research participant meet in shared '“positional spaces", where the situated knowledge of both parties in the interview encounter, engender a level of trust and co-operation' (Mullings 1999, quoted in Valentine 2002, 119).

\section{The risk of personal interest}

The potential danger of disabled academics undertaking work in the subfield of disability geography is that the shared experiences of impairment and disability between researcher and participant may be overestimated. Similar to the

\section{[311]}

critique within feminist geography that women possess an innate understanding of other women, it is vital to emphasise that other kinds of social difference, including gender, sexuality, age, class and ethnicity influence experiences of disability. Moreover, different experiences of impairment also complicate the idea of a shared experience of disability. Valentine $(2002,118)$, following Kobayashi (1994), argues that assumptions of inherent insider positionings should be "criticized as a naïve and dangerous form of essentialism because they uncritically attribute particular connection or a rapport to physical attributes'. Within disability geography, researchers must be attuned to the power relationships between researcher and participant - a personal connection to the field is not enough to defeat academic privilege. Chouinard contends that

even if the researcher is disabled, their particular, situated experiences of disability are not sufficient to enable them to speak for disabled persons more generally or to negate the privilege of their position as an academic researcher (albeit probably one at the margins of academic power). $(2000,73)$

With the dangers of appropriating the voices of research participants, and the historically exploitive relationship between able-bodied researchers and disabled participants, it could be cynically suggested that establishing a personal connection to the field is a way of heading off these concerns, giving credibility (and therefore power) to the researcher for appearing reflexive. Yet, while awareness of disability and ableism is 'the right thing to express', it is no substitute or guarantee for emancipatory research (see Vanderbeck 2005).

Another perhaps more established risk is that the personal nature of the subfield is perceived as a requirement by other geographers. It has been my anecdotal experience that some geographers feel they have nothing to add to the subfield as they consider themselves 'able-bodied' - that it is not their place - and the personal motivations of many geographers in the field reinforces this myth for them. The assumption that work done by researchers without a personal connection to the field will necessarily be lacking in insight needs to be challenged. Although academics (both disabled and non-disabled) and participants often privilege insider status, Bridges contends that 'this does not automatically attach special authority (though it might attach special interest) to their own representations of that experience' $(2001,374)$. This is a vital distinction that opens up the field of disability geography to those who consider themselves outsiders, as successful research depends on the ethical and political commitments of the researchers rather than their level of personal identification with the subject. Another possible reason why 'abled' geographers often feel that they have little to add to the subfield relates to the deep unease and denial of the disabled body. The study of disability involves engaging in what is positioned as abject; for Sibley, quoting Kristeva,

decay, infection, disease, corpse [sic], etc stand for the danger in identity that comes from without: the ego threatened by the non-ego, society threatened by its outside, life by death. (Sibley 1995, 8)

Engaging with disability means acknowledging how society treats people with disabilities, as well as the messy, sometimes painful, lived realities of the body. Researchers in the field have challenged this good/ bad binary of ability/disability by suggesting 'Our task is to show that what seems marginal can actually become crucial in our understanding of social processes'. A way of making disability research in geography more diverse involves a wider critique of ableism, which every citizen invariably encounters whether through temporary injury or old age. One respondent comments that non-disabled persons can also be affected by notions of ableness through the ways in which contemporary workplaces promote a kind of 'hyper-ability' which is detrimental to so many facets of our life including relationships with family and friends.

Seeing disability geography as an important part of geography involves understanding disabled persons' experiences as part of larger engagement with difference in which geographers are already interested, as well as personalising ableism by showing that it affects everyone. Yet this goal remains a difficult shift of perceptions. Non-disabled geographers who do engage with disability may be uneasy about their position - scared of making a mistake and 'getting it wrong'. While committed to emancipatory research, geographers who considered themselves to be nondisabled can be anti-ableist, yet both uncomfortable with the power relations implicit in their research, and intimidated by the mandates of the disability rights movement (for a discussion of non-disabled researchers as 'parasites, pawns and partners', see Stone and Priestley 1996).

A final risk of personal connections to disability geography is that the prevalence of the personal seems to overwhelm other aspects of the subfield. When asked what brought them to the subfield, very few participants cited work done in the field. Instead, one respondent argued we need a better understanding of social theory and the relevance of it to the disability literature . . I find the disability and geography set a bit confining.

While disability geography is a centre for critical research on disability, it does not appear to generate theoretical approaches or ways of new thinking about difference. With exceptions, researchers seem to be drawn to the field to research a particular topic first, where they then add in theories and conceptual frameworks that engage with disability. Perhaps this situation is why

This corpus, while lively and important, is characterised by its marginality at international conferences, in geographical journals and textbooks, as well as a lack of influence on debates outside of geography. (Imrie and Edwards 2007, 2)

Disability geography must have more at its core than passionate researchers - it needs a stronger understanding of critical theory and the impact of ableism across society. It needs to offer the discipline new ways of looking at difference - theories that can be scaled up and used widely in geography. Some work has already been done in this area, yet much remains in grey literature, or within conference sessions attended by few outside the subfield.

\section{Moving forward}

The strength of disability geography lies in the talent and commitment of the researchers active in the subfield. A personal relationship to the subfield can be very important, as it drives passionate, emancipatory scholarship. Yet, the subfield must evolve to have other strengths, to draw in 
new people who don't claim a personal link to disability. Otherwise I believe the subfield's ideas won't become integral to the discipline in the way that feminist geography has, and that disability will remain marginalised and overlooked by mainstream geography. It is these risks - the assumption that a subfield that engages wholly with the personal is exclusionary, and that the personal oblates theoretical and methodological innovation - that are the main areas of challenge for the future of the subfield.

In order to continue producing relevant, critical research, disability geography needs to attract more researchers - with and without a personal connection to the field. Besides getting students interested in the subfield through increased attention in undergraduate (not just graduate) courses, drawing more 'non-personal' researchers into the field could start with repositioning work they already do, seeing it as a part of disability geography, and perhaps renegotiating relationships with health geography and critical social geography. Moreover, while disabled people have had a difficult relationship with nondisabled researchers, it is their methods and not their abilities that have been problematic, and any researcher with an emancipatory framework needs to be welcomed in the field (Bridges 2001; Kitchin 2000; Tregaskis and Goodley 2005). One respondent hopes for 'the appearance and acceptance of more disabled researchers' by challenging ableist practices in universities and academia in general. Another suggests that the field has been growing but underground. She calls for

greater formal reporting, including via scholarly publications of the large amount of postgraduate work undertaken on disablement in geography. Continuing the research process through to publication will widen the appeal of the subfield, as greater numbers of people are exposed to its high quality of scholarship.

Second, as with any relatively new area of study, several respondents thought a greater historical perspective and a stronger grounding in theory would make disability research in geography more rigorous, and appeal to people without a personal connection to the field (see also Imrie and Edwards 2007). Although disability geography mostly works from a social model of disability (adapted from disability studies), several of my respondents felt that current research should be more strongly grounded in theory instead of one dominant model. One relates that any sort of exaltation of any particular knowledge is dangerous, especially in the sense of intellectual stagnation and perhaps closing off of innovative ideas. Asserting dominance, rightness, or accuracy of a particular 'model', for example, does more harm than good in that it forecloses engagement with other types of engagements that could be trying to focus on other dimensions of disability. [

313]

Exploring social theory concerning other forms of difference and ways of looking at the world can strengthen disability geography through shared aims and usable frameworks for analysis. Stronger linkages could productively be made with a wide range of geographic scholarship, particularly emotional geographies, as so much of the effects of ableism and exclusion are negotiated by emotion (Davidson et al. 2005) as well as geographies of the lifecourse (Teather 1999), which usefully theorises time and space in relation to everyday lived experiences. Using theory familiar to those not familiar with disability research will also make disability geography more appealing and accessible to academics, enmeshing disability in other subfields of geography. It is important that disability geography reaches out to the rest of the discipline in these ways, while being careful not to sacrifice the unique, embodied knowledge of disabled people and their experiences of space.

Note 1 The Social Sciences and Humanities Research Ethics Board at the University of Toronto approved the informed consent procedures, and gave the project ethical approval.

\section{References}

Beazley S, Moore M and Benzie D 1997 Involving disabled people in research: a study of inclusion in environmental activities in Barnes $C$ and Mercer $G$ eds Doing disability research The Disability Press, Leeds 142-57

Bridges D 2001 The ethics of outsider research Journal of Philosophy of Education 35 371-86

Browne K 2005 Placing the personal in pedagogy: engaged pedagogy in 'feminist' geographical teaching Journal of Geography in Higher Education $29339-54$

Butler J 1990 Gender trouble: feminism and the subversion of identity Routledge, New York

Butler R 1994 Geography and visually-impaired and blind populations Transactions of the Institute of British Geographers 19 366-8

Butler R and Parr H 1999 Mind and body spaces: geographies of illness, impairment and disability Routledge, London

Chouinard V 2000 Getting ethical: for inclusive and engaged geographies of disability Ethics, Place and Environment 370-80

Chouinard V and Grant A 1995 On being not even anywhere near 'the project': ways of putting ourselves in the picture Antipode 27 137-66

Davidson J, Bondi L and Smith M 2005 Emotional geographies Ashgate, Aldershot England K 1994 Getting personal: reflexivity, positionality, and feminist research

The Professional Geographer 46 80-9

Gleeson B 1996 A geography for disabled people? Transactions of the Institute of British Geographers 21 387-96

Golledge R G 1993 Geography and the disabled: a survey with special reference to vision impaired and blind populations Transactions of the Institute of British Geographers 18 63-85

Golledge R G 1996 A response to Gleeson and Imrie Transactions of the Institute of British Geographers 21 404-11

Hansen N E and Philo C 2007 The normality of doing things differently: bodies, spaces and disability geography Tijdschrift voor Economische en Sociale Geografie 98 493-506

Imrie R 1996 Ableist geographies, disablist spaces: towards a reconstruction of Golledge's 'geography and the disabled' Transactions of the Institute of British Geographers $21397-403$

Imrie R and Edwards C 2007 The geographies of disability: reflections on the development of a sub-discipline Geography Compass 11-18

Katz C 1994 Playing the field: questions of fieldwork in geography The Professional Geographer 46 67-72

Kearns R A and Moon G 2002 From medical to health geography: novelty, place and theory after a decade of change Progress in Human Geography 26 605-25

Kitchin R 2000 The researched opinions on research: disabled people and disability research Disability \& Society $1525-47$

Kobayashi A 1994 Coloring the field: gender, 'race' and the politics of fieldwork The Professional Geographer 46 73-80

Mahtani M 2004 Mapping gender and race in the academy: the experiences of women of colour faculty and graduate students in Britain, the US and Canada Journal of Geography in Higher Education 28 91-9

McCoyd J L M and Schwaber Kerson T 2006 Conducting intensive interviews using email: a serendipitous comparative opportunity Qualitative Social Work 5 389-406

Morris J 1992 Personal and political: a feminist perspective on researching physical disability Disability \& Society 7 157-66

Moss P 1999 Autobiographical notes on chronic illness in Butler R and Parr H eds Mind and body spaces: geographies of illness, impairment and disability Routledge,

London 155-66

Moss P 2001 Placing autobiography in geography Syracuse University Press, Syracuse

Moss P and Matwychuk M 2000 Beyond speaking as an 'as A' and stating the 'etc.': toward engaging a praxis of difference Frontiers $2182-104$

Park D, Radford J and Vickers M 1998 Disability studies in human geography Progress in Human Geography 22 208- 33

Rose G 1993 Feminism and geography: the limits of geographical knowledge Polity Press, Cambridge

Rose G 1997 Situating knowledges: positionality, reflexivities and other tactics Progress in Human Geography 21 305-20 [314]

Shah S 2006 Sharing the world: the researcher and the researched Qualitative Research 6 207-20

Shakespeare T 2006 Disability rights and wrongs Routledge, London

Sibley D 1995 Geographies of exclusion: society and difference in the West Routledge, London

Stone E and Priestley M 1996 Parasites, pawns and partners: disability research and the role of non-disabled researchers The British Journal of Sociology 47 699-716

Teather E K 1999 Embodied geographies: space, bodies and rites of passage Routledge, London 
Tregaskis C and Goodley D 2005 Disability research by disabled and non-disabled people: towards a relational methodology of research production International Journal of Social Research Methodology 8 363-74

Valentine G 2002 People like us: negotiating sameness and difference in the research process in Moss P ed Feminist geography in practice: research and methods Blackwell, Oxford 116-26

Vanderbeck R M 2005 Masculinities and fieldwork: widening the discussion Gender, Place and Culture 12 387-402

Worth N 2005 Current discussions in geographies of disability MA thesis, University of Toronto 